\title{
Importance of Breeding Ecology and Territorial Behaviour of Indian Black Robin (Saxicoloides fulicata leucoptera) for its Conservation
}

\author{
Wickramasinghe S.*, Nandapala K.M.A., Muthuthanthirige D.L. \\ ${ }^{1}$ Department of Biological Sciences, Rajarata University, Sri Lanka \\ *sriwick@gmail.com
}

\begin{abstract}
Indian Black Robin (Saxicoloides fulicata leucoptera) is one of the territorial bird found in scrub forest, rocky areas, open grasslands and near human residence and distributed throughout the country in all climatic zones. Breeding success of birds can be depended on the size of the territory. Territory size can be varying according to breeding season and different locations they occupied. Present study attempted to understand the breeding ecology and territorial behavior of black robin in both breeding and non-breeding seasons. The data were collected using scan sampling and focal animal sampling from 2014 to 2017 in adjacent to the Mihintale sanctuary. The behavioral and territory variations were checked by using a dummy of black robin. ArcGIS v10.3 and Minitab v17 were used for data analysis. The breeding season of black robin lasted nearly three months twice a year from March to June and July to September. Courtship behaviour was started beginning of April and nest building was performed by both male and female. The nest building period averaged $13.25 \pm 0.96$ days. Ten nests were recorded within the study period whilst 4 of them were successful and 6 were pseudo nests. Nests were observed at different places such as rocky areas, rock fragments and joisters of resident places. The clutch size was 2-4 and eggs were whitish in background with small brownish blotches. Average incubation period was $11 \pm 3.4$ days. Both male and female fed the chicks after hatching. Foraging sites were mostly nearby roads, human associated places and live foliage. As a percentage, male used to feed chicks $69.23 \%$ and female $30.77 \%$ within the observed period. There were 12 territories recorded within the study period. The territorial areas were changed according to the members of the group and the breeding season. Territory size ranged from $617 \mathrm{~m}^{2}$ to $5,050 \mathrm{~m}^{2}$ and smaller territories were recorded during the non breeding period while sizes were larger during the breeding period. Results suggest that this species require sufficient habitats to demarcate their territory and nesting. Hence maintain the gardens and shady areas are recommended to conserve this species in domestic areas.
\end{abstract}

Keywords: Black Robin, Territory, Nests, Conservation

Proceedings of the $22^{\text {nd }}$ International Forestry and Environment Symposium 2017 of the Department of Forestry and Environmental Science, University of Sri Jayewardenepura, Sri Lanka 